Please do not remove this page

RMIT

UNIVERSITY

\title{
Reliability of ultrasonographic measurement of the architecture of the vastus lateralis and gastrocnemius medialis muscles in older adults
}

Selva Raj, Isaac; Bird, Stephen; Shield, Anthony

https://researchrepository.rmit.edu.au/esploro/outputs/9921858396601341/filesAndLinks?institution=61RMIT_INST\&index=null

Selva Raj, I., Bird, S., \& Shield, A. (2012). Reliability of ultrasonographic measurement of the architecture of the vastus lateralis and gastrocnemius medialis muscles in older adults. Clinical Physiology and Functional Imaging, 32(1), 65-70. https://doi.org/10.1111/j.1475-097X.2011.01056.x

Document Version: Accepted Manuscript

Published Version: https://doi.org/10.1111/j.1475-097X.2011.01056.x

Repository homepage: https://researchrepository.rmit.edu.au

(c) 2011 The Authors. Clinical Physiology and Functional Imaging (c) 2011 Scandinavian Society of Clinical

Physiology and Nuclear Medicine

Downloaded On 2023/04/27 01:13:35 +1000 
Thank you for downloading this document from the RMIT Research Repository.

The RMIT Research Repository is an open access database showcasing the research outputs of RMIT University researchers.

RMIT Research Repository: http://researchbank.rmit.edu.au/

\section{Citation:}

Selva Raj, I, Bird, S and Shield, A 2012, 'Reliability of ultrasonographic measurement of the architecture of the vastus lateralis and gastrocnemius medialis muscles in older adults', Clinical Physiology and Functional Imaging, vol. 32, no. 1, pp. 65-70.

See this record in the RMIT Research Repository at:

http://researchbank.rmit.edu.au/view/rmit:14816

Version: Accepted Manuscript

Copyright Statement: @ The Authors. Clinical Physiology and Functional Imaging @ 2011 Scandinavian Society of Clinical Physiology and Nuclear Medicine

Link to Published Version:

http://dx.doi.org/10.1111/j.1475-097X.2011.01056.x 
This is the peer reviewed version of the following article:

Selva Raj, I, Bird, S and Shield, A 2012, 'Reliability of ultrasonographic measurement of the architecture of the vastus lateralis and gastrocnemius medialis muscles in older adults', Clinical Physiology and Functional Imaging, vol. 32, no. 1, pp. 65-70 which has been published in final form at:

http://dx.doi.org/10.1111/j.1475-097X.2011.01056.X

This article may be used for non-commercial purposes in accordance With Wiley Terms and Conditions for self-archiving. 
Running title: RELIABILITY OF ULTRASONOGRAPHY

Reliability of Ultrasonographic Measurement of the Architecture of the Vastus Lateralis and Gastrocnemius Medialis Muscles in Older Adults Isaac Selva Raj*†, Stephen R. Bird ${ }^{\dagger}$, and Anthony J. Shield

Royal Melbourne Institute of Technology University
Discipline of Exercise Sciences
School of Medical Sciences
Bundoora West Campus
PO Box 71
Bundoora
Victoria 3083
Australia

Queensland University of Technology
School of Human Movement Studies
Level 4, O Block A Wing
QUT Kelvin Grove Campus
Ring Road, Kelvin Grove
Queensland 4059
Australia

*Address for correspondence:

Isaac Selva Raj

Discipline of Exercise Sciences

School of Medical Sciences

RMIT University

Bundoora West Campus

PO Box 71

Bundoora

Victoria 3083

Australia

Phone: 61399257037

Fax: 61394678181

E-mail: isaacselva.raj@rmit.edu.au

Key words: Ageing, muscle architecture, reliability

Abstract 
Objective. To determine the test-retest reliability of measurements of thickness, fascicle length $\left(\mathrm{L}_{\mathrm{f}}\right)$ and pennation angle $(\theta)$ of the vastus lateralis $(\mathrm{VL})$ and gastrocnemius medialis (GM) muscles in older adults.

Participants. Twenty-one healthy older adults (11 men and 10 women; average age 68.1 \pm 5.2 years) participated in this study.

Methods. Ultrasound images (probe frequency 10MHz) of the VL at two sites (VL site 1 and 2) were obtained with participants seated with knee at $90^{\circ}$ flexion. For GM measures, participants lay prone with ankle fixed at $15^{\circ}$ dorsiflexion. Measures were taken on two separate occasions, 7 days apart (T1 and T2).

Results. The ICCs $(95 \%$ CI $)$ were: VL site 1 thickness $=0.96(0.90-0.98)$; VL site 2 thickness $=0.96(0.90-0.98), \mathrm{VL} \theta=0.87(0.68-0.95), \mathrm{VL} \mathrm{L}_{\mathrm{f}}=0.80(0.50-0.92), \mathrm{GM}$ thickness $=0.97(0.92-$ 0.99), GM $\theta=0.85(0.62-0.94)$ and $\mathrm{GM} \mathrm{L}_{\mathrm{f}}=0.90(0.75-0.96)$. The $95 \%$ ratio limits of agreement (LOAs) for all measures, calculated by multiplying the standard deviation of the ratio of the results between $\mathrm{T} 1$ and $\mathrm{T} 2$ by 1.96 , ranged from 10.59 to $38.01 \%$.

Conclusion. The ability of these tests to determine a real change in VL and GM muscle architecture is good on a group level but problematic on an individual level as the relatively large $95 \%$ ratio LOAs in the current study may encompass the changes in architecture observed in other training studies. Therefore, the current findings suggest that B-mode ultrasonography can be used with confidence by researchers when investigating changes in muscle architecture in groups of older adults, but its use is limited in showing changes in individuals over time. 


\section{Introduction}

Skeletal muscle architecture plays an important role in the function of muscles in humans (Blazevich \& Sharp, 2005; Narici, 1999). Specifically, muscle fascicle length plays a role in force generation during high-speed contractions, while fascicle pennation angle and muscle thickness are important factors for overall force generation (Blazevich \& Sharp, 2005). Ultrasonography has become a popular method for characterising muscle architecture due to its safety and non-invasive nature (Narici, 1999). Previous research has demonstrated the reliability of muscle architecture measurements by B-mode ultrasound imaging in adults (Blazevich, Cannavan, Coleman, \& Horne, 2007; Maganaris, Baltzopoulos, \& Sargeant, 1998; Narici et al., 1996) and young children (Legerlotz, Smith, \& Hing, 2010), but there is a lack of data in this area in older adults. However, cross-sectional studies have demonstrated that muscle architecture, or specifically, muscle thickness, fascicle length $\left(\mathrm{L}_{\mathrm{f}}\right)$ and fascicle pennation angle $(\theta)$ are reduced in older adults compared to their young counterparts (Morse, Thom, Birch, \& Narici, 2005; Narici, Maganaris, Reeves, \& Capodaglio, 2003; Thom, Morse, Birch, \& Narici, 2007). These differences mean that the reliability measures established for young adults and children may not be applicable to older adults. Additionally, since the aforementioned age associated changes result in a decline in functional capacity, health and quality of life, a number of exercise studies have been undertaken to investigate the effects of various resistance training modalities on muscle architecture in older adults and to assess whether the age associated changes can be ameliorated or reversed (Morse, Thom, Mian, Birch, \& Narici, 2007; Reeves, Maganaris, Longo, \& Narici, 2009; Reeves, Narici, \& Maganaris, 2004a, 2004b, 2006; Suetta et al., 2008). Therefore, information on the reliability of ultrasound measures of muscle architecture in older adults is needed to provide researchers with an indication of the size of differences required to observe significant differences 
between or within groups, and help in the planning of future research studies (Legerlotz, et al., 2010).

The aim of the current study was to determine the reliability of measurements of muscle thickness, fascicle length and pennation angle of the vastus lateralis (VL) and gastrocnemius medialis (GM) muscles in older adults using B-mode ultrasound imaging. 
Methods

\section{Participants}

The study was approved by the University Human Research Ethics Committee and was conducted according to the Declaration of Helsinki (Puri, Suresh, Gogtay, \& Thatte, 2009). Participants were recruited from local retirement villages via flyers. Twenty-one healthy community-dwelling older adults (11 men and 10 women) participated in this study. Participants were excluded from the study if they were identified during a preliminary health screening as having any relevant orthopaedic problem or if they were undertaking resistance training that included leg exercises. Written informed consent was obtained from all participants before entry into the study. Participants were instructed to maintain their regular level of physical activity throughout the experimental period.

\section{Study Design}

A single investigator acquired the images from all participants on two separate test sessions (T1 and T2), which were separated by 7 to 14 days. Test sessions were held at the same time of day for each participant. A second investigator, who was blinded to the identity of the participants, was then employed to analyse the images.

\section{Muscle Architecture}

Real-time B-mode ultrasonography (LOGIQ I, GE Healthcare, Wauwatosa, Wisconsin, USA) was used to measure fascicle pennation angle, fascicle length and muscle thickness of the vastus lateralis and gastrocnemius medialis muscles. The leg to be tested was chosen at random, and the same leg was tested at both test sessions. The $42 \mathrm{~mm}$ long, 10 $\mathrm{MHz}$ linear-array ultrasound transducer was coated with sufficient water-based transmission 
gel to ensure that clear images of the muscles were obtained without the need to compress the muscles during examination.

A site $62.5 \%$ proximal between the anterior superior iliac spine and the superior aspect of the patella on the mid-sagittal plane of the thigh was marked (VL site 1) on the skin. Another site at the same position along the thigh as VL site 1 on the mid-coronal plane on the lateral side of the thigh was also marked (VL site 2). Participants then sat with the knee angle fixed at $90^{\circ}$ (see Figure 1). These sites were chosen for examination as pilot testing revealed minimal fascicle curvature at these sites when participants sat in this position. The ultrasound transducer was placed over the muscle at VL site 2 and when clear images of the muscle fascicles, and the superficial and deep aponeuroses were obtained, three images were recorded. These images, recorded to a depth of $6 \mathrm{~cm}$ from the transducer surface, were used to measure VL fascicle length and pennation angle. To measure vastus lateralis muscle thickness clear images of the superficial and deep aponuroses and the femur were obtained and another three images were each recorded to a depth of $9 \mathrm{~cm}$ at both VL site 1 and VL site 2 (Blazevich, Gill, Deans, \& Zhou, 2007). The greater recording depth was chosen for muscle thickness measurements as pilot testing revealed that this depth was required to visualise the femur.

To assess gastrocnemius medialis muscle architecture and thickness, participants were asked to lie prone on the bench with their feet hanging off the edge (Narici, et al., 2003). A modified night splint was placed on the foot and lower leg to fix the ankle joint angle at $15^{\circ}$ dorsiflexion. The ultrasound transducer was placed on a site on the muscle $30 \%$ proximal between the lateral malleolus of the fibula and the lateral condyle of the tibia (see Figure 2). This site was chosen for examination as pilot testing revealed minimal fascicle curvature at this site when participants were lying in this position. Once clear images of the muscle 
fascicles, and the superficial and deep aponeuroses were obtained, three images were recorded to a depth of $6 \mathrm{~cm}$ from the surface of the transducer.

After the first test session, a clear plastic sheet was placed over the participants' anterior thigh and posterior lower leg and the examination sites and any permanent blemishes on the skin, as well as the examination sites, were marked on the sheet (Blazevich, Gill, et al., 2007). Before the second test session, holes were made on the clear plastic sheets at the marked examination sites. The sheets were then placed over the skin and aligned with the marked blemishes before the examination sites were marked with a pen on the skin. All images were recorded digitally and analysed using computer software (ImageJ, U. S. National Institutes of Health, Bethseda, Maryland, USA).

Vastus lateralis muscle thickness was defined as the distance between the superficial aponeurosis and the femur, and gastrocnemius medialis muscle thickness was defined as the distance between the superficial and deep aponeuroses. Pennation angle was measured as the angle between the muscle fascicles and the deep aponeurosis, and fascicle length was measured as the length of a fascicle between its insertions at the superficial and deep aponeurosis. Where the fascicles extended beyond the recorded image, fascicle length was estimated from muscle thickness and fascicle pennation angle using the following equation (Abe, Kumagai, \& Brechue, 2000):

Fascicle length $=$ muscle thickness $\cdot \sin \theta^{-1}$ where $\theta$ is muscle fascicle pennation angle determined by ultrasonography.

\section{Statistical Analyses}

To assess reliability, intraclass correlation coefficients (ICC) were calculated for each measure of muscle thickness, pennation angle and fascicle length. Since the average results from three images were used for analysis, the two-way mixed model of average-measure 
reliabilities $\left(\mathrm{ICC}_{3,1}\right)$ was used. If there was evidence of non-normality in the data, as assessed by the Kolmogorov-Smirnov test, the data were natural log-transformed before calculation of ICCs (Atkinson \& Nevill, 1998).

In addition, Bland-Altman plots (Bland \& Altman, 1986) of the difference in results between $\mathrm{T} 1$ and $\mathrm{T} 2$ against the mean of $\mathrm{T} 1$ and $\mathrm{T} 2$ for each participant were generated to calculate the $95 \%$ limits of agreement (LOA). The presence of heteroscedasticity in the data sets was objectively assessed by plotting the absolute differences against the mean of $\mathrm{T} 1$ and T2, and calculating the correlation coefficient (Atkinson \& Nevill, 1998). The presence of heteroscedasticity can lead to the $95 \%$ limits of agreement to be underestimated at the higher end of measured values, and overestimated at the lower end of measured values (Atkinson \& Nevill, 1998). If heteroscedasticity was not present, the LOA were calculated as described elsewhere (Atkinson \& Nevill, 1998). If heteroscedasticity was found to be present, the ratio of the two results from $\mathrm{T} 1$ and $\mathrm{T} 2$ for each participant was calculated and plotted against the mean of T1 and T2. The 95\% ratio LOA were then calculated as described by Bland and Altman (1999) and Eksborg (1981). Paired $t$-tests with equal variances assumed were used to assess systematic bias in the results from $\mathrm{T} 1$ and $\mathrm{T} 2$.

Results were considered significant at $P<0.05$, and statistical analyses were performed using SPSS 17.0 (SPSS, Chicago, IL). 
Results

Participants' demographics are detailed in Table 1. Table 2 details the descriptive statistics of the ultrasound measures. Paired $t$-tests revealed no systematic bias in any of the measures. The 95\% LOA are illustrated graphically in the Bland-Altman plots (see Figure 3).

Table 3 presents the ICCs between T1 and T2. The upper and lower 95\% confidence limits for the ICCs and the $95 \%$ ratio LOAs are also included in Table 3 . In general, the ICCs for the thickness measures were higher than the ICCs for $\mathrm{L}_{\mathrm{f}}$ and $\theta$ for both the VL and GM muscles. The $95 \%$ confidence intervals for the ICCs tended to be narrower for the thickness measures than for $\mathrm{L}_{\mathrm{f}}$ and $\theta$ measures. The ICCs for all measures were good, ranging from 0.80 to 0.97 .

The 95\% ratio LOAs for VL site 1 thickness, VL site 2 thickness, VL $\theta$, VL $L_{f}, G M$ thickness, GM $\theta$ and $\mathrm{GM} \mathrm{L}_{\mathrm{f}}$ were $0.99 \times / \div 1.17,0.98 \times / \div 1.11,1.04 \times / \div 1.34,1.05 \times / \div 1.38$, $1.01 \times / \div 1.13,1.03 \times / \div 1.24$ and $1.00 \times / \div 1.22$ respectively 


\section{Discussion}

The muscle architectural measurements obtained in the current study agree well with measurements of the VL and GM muscles obtained in previous studies in older adults using B-mode ultrasonography (Morse, et al., 2005; Narici, et al., 2003; Reeves, et al., 2009; Suetta, et al., 2008; Thom, et al., 2007). The ultrasound measurements of GM muscle architecture in this study also agree closely with direct measurements of GM muscle architecture in a cadaver of a 62 year old male (Narici, et al., 1996). It should be noted, however that the reliability data presented here are specific to the data collection protocol followed in the current study.

The results of the study demonstrated good to very good relative reliability, ranging from 0.96 to 0.97 for thickness measurements, 0.85 to 0.87 for $\theta$ measurements and 0.80 to 0.90 for $\mathrm{L}_{\mathrm{f}}$ measurements. However, the $95 \%$ confidence intervals of the ICCs for the $\mathrm{L}_{\mathrm{f}}$ and $\theta$ measurements tended to be wider than those for the thickness measurements. This indicates that a larger sample size may be needed to attain greater precision of estimates of ICCs for $\mathrm{L}_{\mathrm{f}}$ and $\theta$ measurements (Atkinson \& Nevill, 2001). The measurements were comparable to the ICCs of 0.88 to $0.97,0.90$ to 0.99 and 0.76 to 0.86 for VL muscle thickness, $\theta$ and $\mathrm{L}_{\mathrm{f}}$ respectively obtained by Blazevich et al. (2007) in young adults. The results also agree closely with those obtained by Legerlotz and colleagues (2010) from the GM muscles of young children aged four to 10 years old. This suggests that, despite the varying ages of the participants and differing knee and ankle joint positions during measurements in these studies, B-mode ultrasonography and the analysis of the images from this method is a reliable method of characterising muscle architecture on a group level.

However, as observed by Legerlotz et al. (2010), muscle architecture measurements have a high degree of inter-individual variability, which can result in higher ICCs than expected. Therefore, to gain a better understanding of the reliability of using B-mode 
ultrasonography to measure muscle architecture, we have produced Bland-Altman plots (Bland \& Altman, 1986) and calculated 95\% ratio LOAs for each measure. In this way, we were able to characterise the absolute reliabilities of these measures and illustrate systematic bias, if present, between $\mathrm{T} 1$ and $\mathrm{T} 2$. For example, the 95\% ratio LOA for GM thickness was 1.13 or $12.56 \%$. This means that for a new individual from this older adult population, there is a $95 \%$ probability any two tests would differ due to measurement error by no more than $12.56 \%$ in either the positive or negative direction. This result is comparable to the $95 \%$ ratio LOA of 1.13 or $13 \%$ observed by Legerlotz et al. (2010) for thickness measures of the GM muscle in young children. Unfortunately, Legerlotz et al. (2010) did not report 95\% LOAs for $\theta$ and $\mathrm{L}_{\mathrm{f}}$. To the knowledge of the authors, no other studies have reported $95 \%$ LOAs or ratio LOAs for muscle architecture measurements, illustrating the need for more research in this area.

An interesting observation of the results of the current study is that the $\mathrm{L}_{\mathrm{f}}$ measurements of the GM muscle are more reliable (both absolute and relative reliability) than $\mathrm{L}_{\mathrm{f}}$ measurements of the VL muscle. This could be because of the shorter fascicle lengths in the GM muscle, meaning that less extrapolation outside the field of view of the ultrasound transducer is necessary to quantify fascicle lengths.

Although the very limited evidence available seems to suggest that the reliability of the methods of characterising VL and GM muscle architecture in the current study is comparable to other studies, the absolute reliabilities of VL and GM $\theta$ and $\mathrm{L}_{\mathrm{f}}$ may be wider than desirable. This is because typical average changes observed in previous studies involving 14 weeks of resistance training with elderly adults are up to $35 \%$ for VL $\theta$ and up to $20 \%$ for $\mathrm{VL} \mathrm{L}_{\mathrm{f}}$ (Reeves, et al., 2009; Reeves, et al., 2004a), while 95\% ratio LOAs for VL $\theta$ and VL $\mathrm{L}_{\mathrm{f}}$ observed in the current study are $33.74 \%$ and $38.01 \%$ respectively. These results therefore indicate that these measures may not be sensitive enough to detect real $\theta$ and $\mathrm{L}_{\mathrm{f}}$ 
changes in individuals. One reason for this could be the method of using clear plastic sheets to trace the examination sites as well as permanent blemishes on the skin surface at $\mathrm{T} 1$ to use as reference points in order to examine the same sites on the muscles at T2. Some participants had very few or no blemishes on their skin, making it very difficult to find reference points. This reduced the precision with which measurement sites could be relocated and therefore reduced the accuracy of this method in some cases. Also, Klimstra and colleagues (2007) have previously demonstrated that changes in the orientation of the ultrasound transducer can have an effect on muscle architectural measurements. Since the orientation of the transducer was not standardised between $\mathrm{T} 1$ and $\mathrm{T} 2$ in the current study, this may have been another factor that contributed to the ratio LOAs being wider than desirable.

\section{Conclusion}

In summary, the method of using B-mode ultrasonography described in the current study to characterise VL and GM muscle architecture in older adults has high relative reliability. However, the $95 \%$ LOAs and ratio LOAs are wider than desirable. Therefore, the ability of these tests to determine a real change in VL and GM muscle architecture is good on a group level but problematic on an individual level as the relatively large LOAs and ratio LOAs observed in the current study may encompass the changes in architecture observed in other training studies. Hence, the current findings suggest that B-mode ultrasonography can be used with confidence by researchers when investigating changes in muscle architecture in groups of older adults, but it may not be sensitive enough to detect small changes in muscle architecture in individuals. 
Acknowledgement

The authors would like to acknowledge the contribution of Gabriel Sivaratnam, who assisted with the analysis of ultrasound images.

\section{Conflict of Interest Disclosures}

The authors report no conflicts of interest.

\section{Author Contributions}

Isaac Selva Raj: Substantial contribution to study concept and design, acquisition of data, analysis and interpretation of data. Drafted article for publication and approved final version to be published.

Stephen R. Bird: Substantial contribution to study concept and design and interpretation of data. Revised draft article for important intellectual content and approved final version to be published.

Anthony J. Shield: Substantial contribution to study concept and design and interpretation of data. Revised draft article for important intellectual content and approved final version to be published.

Sponsor's Role

The authors report no sponsors for this project. 


\section{References}

Abe, T., Kumagai, K., \& Brechue, W. F. (2000). Fascicle length of leg muscles is greater in sprinters than distance runners. Med Sci Sports Exerc, 32(6), 1125-1129.

Atkinson, G., \& Nevill, A. M. (1998). Statistical methods for assessing measurement error (reliability) in variables relevant to sports medicine. Sports Med, 26(4), 217-238.

Atkinson, G., \& Nevill, A. M. (2001). Selected issues in the design and analysis of sport performance research. J Sports Sci, 19(10), 811-827.

Bland, J. M., \& Altman, D. G. (1986). Statistical methods for assessing agreement between two methods of clinical measurement. Lancet, 1(8476), 307-310.

Bland, J. M., \& Altman, D. G. (1999). Measuring agreement in method comparison studies. Stat Methods Med Res, 8(2), 135-160.

Blazevich, A. J., Cannavan, D., Coleman, D. R., \& Horne, S. (2007). Influence of concentric and eccentric resistance training on architectural adaptation in human quadriceps muscles. J Appl Physiol, 103(5), 1565-1575.

Blazevich, A. J., Gill, N. D., Deans, N., \& Zhou, S. (2007). Lack of human muscle architectural adaptation after short-term strength training. Muscle Nerve, 35(1), 78-86.

Blazevich, A. J., \& Sharp, N. C. (2005). Understanding muscle architectural adaptation: macro- and micro-level research. Cells Tissues Organs, 181(1), 1-10.

Eksborg, S. (1981). Evaluation of method-comparison data. Clin Chem, 27(7), 1311-1312.

Klimstra, M., Dowling, J., Durkin, J. L., \& MacDonald, M. (2007). The effect of ultrasound probe orientation on muscle architecture measurement. J Electromyogr Kinesiol, 17(4), 504.

Legerlotz, K., Smith, H. K., \& Hing, W. A. (2010). Variation and reliability of ultrasonographic quantification of the architecture of the medial gastrocnemius muscle in young children. Clin Physiol Funct Imaging, 30(3), 198-205. 
Maganaris, C. N., Baltzopoulos, V., \& Sargeant, A. J. (1998). In vivo measurements of the triceps surae complex architecture in man: implications for muscle function. $J$ Physiol, 512 ( Pt 2), 603-614.

Morse, C. I., Thom, J. M., Birch, K. M., \& Narici, M. V. (2005). Changes in triceps surae muscle architecture with sarcopenia. Acta Physiol Scand, 183(3), 291-298.

Morse, C. I., Thom, J. M., Mian, O. S., Birch, K. M., \& Narici, M. V. (2007). Gastrocnemius specific force is increased in elderly males following a 12-month physical training programme. Eur J Appl Physiol, 100(5), 563-570.

Narici, M. V. (1999). Human skeletal muscle architecture studied in vivo by non-invasive imaging techniques: functional significance and applications. J Electromyogr Kinesiol, 9(2), 97-103.

Narici, M. V., Binzoni, T., Hiltbrand, E., Fasel, J., Terrier, F., \& Cerretelli, P. (1996). In vivo human gastrocnemius architecture with changing joint angle at rest and during graded isometric contraction. J Physiol, 496 ( Pt 1), 287-297.

Narici, M. V., Maganaris, C. N., Reeves, N. D., \& Capodaglio, P. (2003). Effect of aging on human muscle architecture. J Appl Physiol, 95(6), 2229-2234.

Puri, K. S., Suresh, K. R., Gogtay, N. J., \& Thatte, U. M. (2009). Declaration of Helsinki, 2008: implications for stakeholders in research. J Postgrad Med, 55(2), 131-134.

Reeves, N. D., Maganaris, C. N., Longo, S., \& Narici, M. V. (2009). Differential adaptations to eccentric versus conventional resistance training in older humans. Exp Physiol, 94(7), 825-833.

Reeves, N. D., Narici, M. V., \& Maganaris, C. N. (2004a). Effect of resistance training on skeletal muscle-specific force in elderly humans. J Appl Physiol, 96(3), 885-892. 
Reeves, N. D., Narici, M. V., \& Maganaris, C. N. (2004b). In vivo human muscle structure and function: adaptations to resistance training in old age. Exp Physiol, 89(6), 675689.

Reeves, N. D., Narici, M. V., \& Maganaris, C. N. (2006). Musculoskeletal adaptations to resistance training in old age. Man Ther, 11(3), 192-196.

Suetta, C., Andersen, J. L., Dalgas, U., Berget, J., Koskinen, S., Aagaard, P., et al. (2008). Resistance training induces qualitative changes in muscle morphology, muscle architecture, and muscle function in elderly postoperative patients. J Appl Physiol, 105(1), 180-186.

Thom, J. M., Morse, C. I., Birch, K. M., \& Narici, M. V. (2007). Influence of muscle architecture on the torque and power-velocity characteristics of young and elderly men. Eur J Appl Physiol, 100(5), 613-619. 
Table 1

Participant demographics

\begin{tabular}{ccccc} 
Participants & $n$ & $\begin{array}{c}\text { Age } \\
\text { (years) }\end{array}$ & Height $(\mathrm{cm})$ & Mass $(\mathrm{kg})$ \\
\hline Males & 11 & $67.1 \pm 4.8$ & $168.5 \pm 10.0$ & $78.5 \pm 11.0$ \\
Females & 10 & $69.3 \pm 5.6$ & $160.7 \pm 5.5^{*}$ & $68.3 \pm 6.3^{*}$ \\
Overall & 21 & $68.1 \pm 5.2$ & $164.8 \pm 8.9$ & $73.7 \pm 10.3$
\end{tabular}

Data presented as mean $\pm \mathrm{SD} ; n=$ number of participants; Asterisk indicates a significant difference between males and females $(P<0.05)$. 
Table 2

Descriptive statistics for muscle architecture measures

\begin{tabular}{ccccc}
\hline Test Name & Test 1 & Test 2 & \% Diff & $P$-value \\
\hline VL site 1 thickness & $3.80 \pm 0.74 \mathrm{~cm}$ & $3.76 \pm 0.80 \mathrm{~cm}$ & -1.1 & 0.42 \\
VL site 2 thickness & $4.50 \pm 0.57 \mathrm{~cm}$ & $4.42 \pm 0.63 \mathrm{~cm}$ & -1.8 & 0.13 \\
VL $\theta$ & $11.2 \pm 3.0^{\circ}$ & $11.4 \pm 2.5^{\circ}$ & 1.8 & 0.51 \\
VL L & $11.1 \pm 2.9 \mathrm{~cm}$ & $11.4 \pm 2.6 \mathrm{~cm}$ & 2.7 & 0.41 \\
GM thickness & $1.79 \pm 0.28 \mathrm{~cm}$ & $1.80 \pm 0.31 \mathrm{~cm}$ & 0.7 & 0.57 \\
GM $\theta$ & $17.8 \pm 2.9^{\circ}$ & $18.2 \pm 2.7^{\circ}$ & 2.2 & 0.38 \\
GM L $_{\mathrm{f}}$ & $5.99 \pm 1.15 \mathrm{~cm}$ & $5.96 \pm 1.15 \mathrm{~cm}$ & -0.5 & 0.84
\end{tabular}

Data presented as mean $\pm \mathrm{SD} ; \%$ Diff $=$ percent mean difference; $\mathrm{VL}=$ vastus lateralis muscle; $\mathrm{GM}=$ gastrocnemius medialis muscle; $\theta=$ muscle fascicle pennation angle; $\mathrm{L}_{\mathrm{f}}=$ muscle fascicle length. $P$-values refer to paired $t$-test between Test 1 and Test 2. 
Table 3

Reliability statistics for muscle architecture measures

\begin{tabular}{ccccc}
\hline Test & ICC & $\begin{array}{c}\text { Lower } \\
\text { confidence } \\
\text { limit }\end{array}$ & $\begin{array}{c}\text { Upper } \\
\text { confidence } \\
\text { limit }\end{array}$ & $\begin{array}{c}\text { 95\% ratio LOA } \\
(\%)\end{array}$ \\
\hline VL site 1 thickness & 0.96 & 0.90 & 0.98 & 17.25 \\
VL site 2 thickness & 0.96 & 0.90 & 0.98 & 10.59 \\
VL $\theta$ & 0.87 & 0.68 & 0.95 & 33.74 \\
VL L $L_{f}$ & 0.80 & 0.50 & 0.92 & 38.01 \\
GM thickness & 0.97 & 0.92 & 0.99 & 12.56 \\
GM $\theta$ & 0.85 & 0.62 & 0.94 & 24.18 \\
GM L & 0.90 & 0.75 & 0.96 & 22.25
\end{tabular}

$\mathrm{VL}=$ vastus lateralis muscle; $\mathrm{GM}=$ gastrocnemius medialis muscle; $\theta=$ muscle fascicle pennation angle; $\mathrm{L}_{\mathrm{f}}=$ muscle fascicle length; $95 \%$ ratio $\mathrm{LOA}=95 \%$ ratio limits of agreement, calculated by multiplying the standard deviation of the ratio of the results between Test 1 and Test 2 by 1.96 . 


\section{Figure Caption}

Figure 1. Photograph of the vastus lateralis (VL) examination set-up.

Figure 2. Photograph of the medial gastrocnemius (GM) examination set-up.

Figure 3. Bland-Altman plots of muscle architecture measurements. Long dashes represent upper and lower $95 \%$ limits of agreement. Short dashes represent the systematic bias. 
Figure 1.

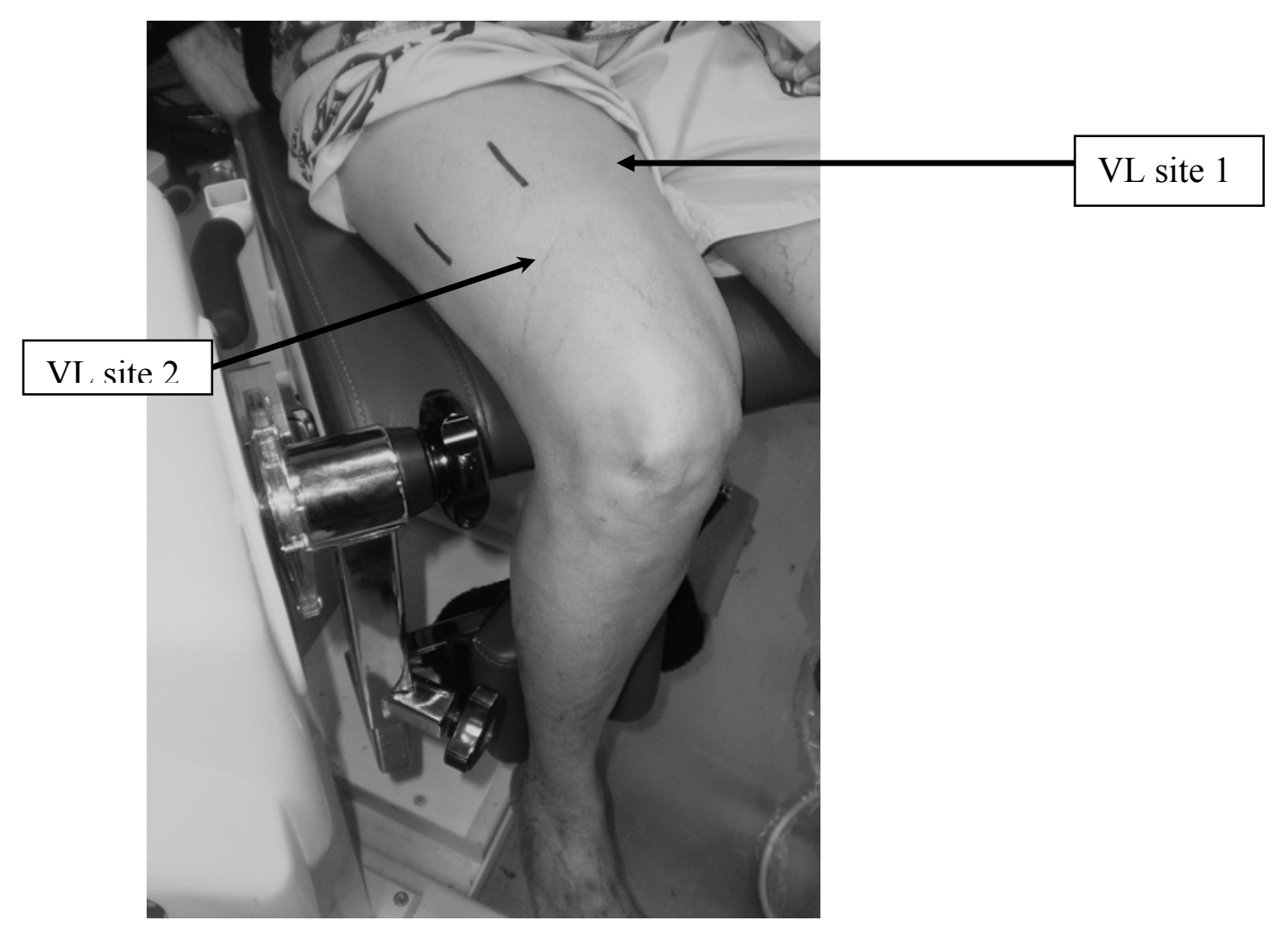


Figure 2.

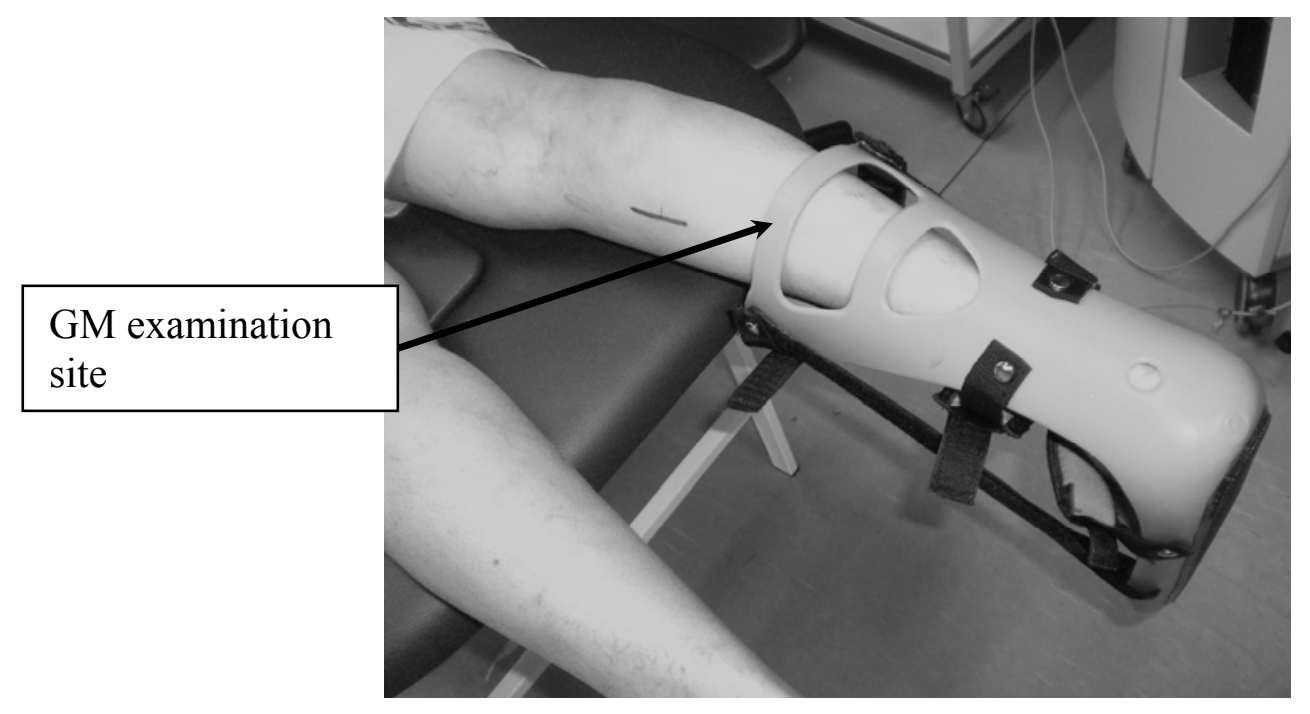


Figure 3.
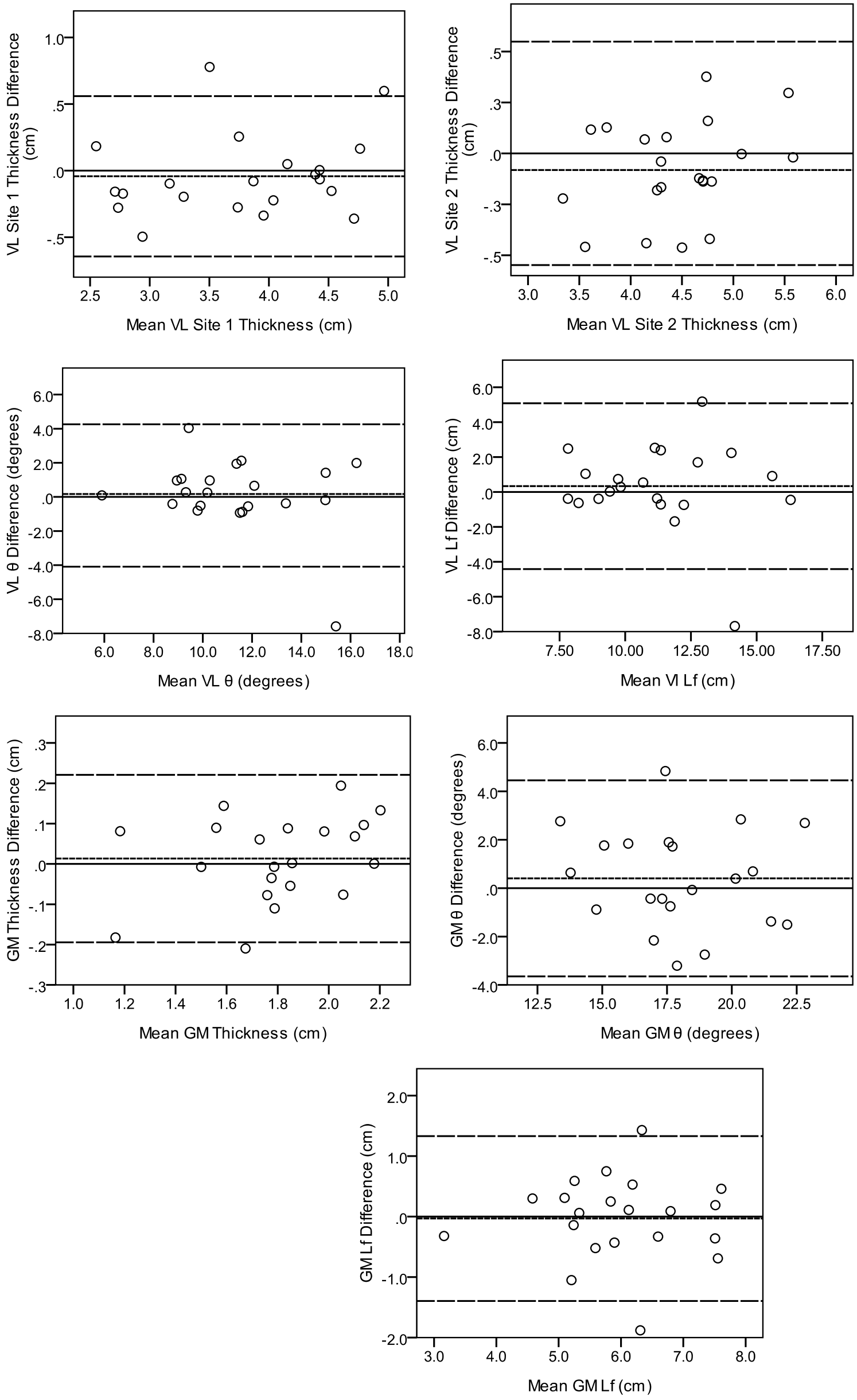